\title{
On precipitation in rapidly solidified aluminium-silicon alloys
}

\author{
P. VAN MOURIK, E. J. MITTEMEIJER, TH. H. DE KEIJSER \\ Laboratory of Metallurgy, Delft University of Technology, Rotterdamseweg 137, \\ 2628 AL Delft, The Netherlands
}

The precipitation of silicon in rapidly solidified AISi alloys was studied. For alloys with 2.4 and 11.0 wt \% Si (2.3 and 10.3 at \% Si, respectively) the lattice parameters of the Alrich and of the Si-rich phases were measured after ageing at 397,425 and $448 \mathrm{~K}$. For alloys with 2.6 and 13.0 wt \% Si crystallite sizes and lattice strains were determined by analysis of the X-ray diffraction line broadening. After ageing the lattice parameters of the Al-rich and the Si-rich phases were influenced by the difference in thermal expansion between both phases. After correction for this effect the amount of silicon dissolved in the Al-rich phase was estimated as a function of ageing time. Quenched-in (excess) vacancies influenced the precipitation kinetics. Activation energies for precipitation appeared to depend on the extent of transformation. Further, quenched-in vacancies caused anomalous maxima in the lattice parameter curves. The behaviour of the lattice microstrains on ageing was explained as a result of the disappearance of stresses due to quenching and the introduction and subsequent dissipation of stresses due to precipitation. After completed precipitation stresses due to the difference in thermal expansion between both phases still exist at room temperature.

\section{Introduction}

Alloys of aluminium and silicon form an important part of aluminium scrap. Liquid quenching [1,2], as compared to solid quenching, enlarges the solid solubility of the alloying elements, thus facilitating the recycling of scrap material. Although the precipitation of silicon in solid-quenched AlSi alloys was the subject of several studies [3-8], few investigations were devoted to precipitation in liquid-quenched AlSi alloys [1,9]. This paper presents results on processes occurring during precipitation in liquid-quenched AlSi alloys. By liquid quenching the silicon solubility may be extended up to the eutectic composition [2], whereas the maximum equilibrium solubility equals 1.58 at \% at $850 \mathrm{~K}$. On liquid quenching all silicon present can rarely be kept in solid solution (cf. Discussion in [2]). Further, vacancies present at elevated temperatures will be retained after quenching. Therefore, the precipitation kinetics are determined by the amount of silicon in solid solution as well as by the excess vacancy concentration.

\section{Excess vacancies in aluminium and its alloys}

From the literature the following picture of the behaviour of excess vacancies during quenching and ageing may be obtained.

In case the quenching rate is sufficiently high $\left(>10^{4} \mathrm{~K} \mathrm{sec}^{-1}[10-12]\right)$ nearly all vacancies present at high temperatures will be retained at room temperature as excess vacancies. In pure aluminium excess vacancies cluster into voids which can collapse into loops during quenching and during ageing subsequent to quenching. The occurrence of voids preceding loop formation was first suggested by Kuhlmann-Wilsdorf and Wilsdorf [13] and was experimentally supported by Kiritani $[14,15]$. The observation of vacancy loops only 
was reported in $[13,16]^{*}$. Since the recovery of quenched pure aluminium has been completed after $1 \mathrm{~h}$ of ageing at room temperature [17-19], the excess vacancies are expected to annihilate at room temperature within the same time.

In the presence of dissolved alloying elements interacting with vacancies, the concentration of excess vacancies can be higher than in pure aluminium $[20,21]$. According to Westmacott et al. [22] the size of the vacancy loops depends on the nature of the alloying element. Alloying with zinc, copper, silver, magnesium and silicon resulted in smaller loops in the order given, indicating an increasing interaction from zinc to silicon between (clusters of) dissolved alloying atoms and vacancies. The majority of the excess vacancies is bound to alloying atoms. This amount will be larger as the interaction between alloying atoms and vacancies increases $[20,21]$. In the case of the AlSi system the "free" excess vacancies will precipitate into vacancy loops during quenching or subsequent ageing. Indeed, it can be deduced from experimental data for aluminium alloys $[3,11,22]$ that only a small fraction of the total excess vacancy concentration, as theoretically calculated according to $[20,21]$, precipitates into vacancy loops. To our knowledge no void formation preceding loop formation has been reported until now for aluminium alloys*. Due to the affinity between vacancies and silicon vacancy loops in AlSi alloys may be stabilized up to rather high temperatures $[6,7]^{\dagger}$. Therefore, in contrast with the case of pure aluminium no significant vacancy annihilation occurs at room temperature (cf. [11] p. 39).

During ageing vacancies are moving through the crystal. According to Ozawa and Kimura [7] vacancy loops can act as temporary sinks. In the presence of a low density of permanent sinks $\$$ the excess vacancies firstly condense into loops. This process continues until a quasi-equilibrium concentration of excess vacancies in the matrix is established. From that moment on a net loss of excess vacancies occurs at permanent sinks which is compensated by the evaporation of the loops.

Because silicon precipitation proceeds via a vac- ancy diffusion mechanism, the annihilation of the excess vacancies will have a great influence on the kinetics of the silicon precipitation. Liquid quenching generally results in higher excess vacancy concentrations than solid quenching does $[23,24]$.

Initial experiments with liquid-quenched AlSi alloys demonstrated the influence of the excess vacancy concentration: as compared to solidquenched specimens, precipitation in liquidquenched specimens can proceed more rapidly (cf. $[3,4]$ to $[1,9]$ ). In accordance with this picture, the activation energy for precipitation after liquid quenching can be lower than after solid quenching (cf. [8] to $[1,9]$ ).

\section{Experimental procedures}

Aluminium alloys with 2.4 and $11.0 \mathrm{wt} \% \mathrm{Si}$ were prepared [2] from $99.998 \mathrm{wt} \% \mathrm{Al}$ and $99.99 \mathrm{wt} \%$ Si. By the melt-spinning technique ribbons with a non-uniform thickness varying between 20 and $150 \mu \mathrm{m}$ were obtained [2]. According to dendritic arm spacing measurements the cooling rate was in the range $10^{6}$ to $10^{7} \mathrm{~K} \mathrm{sec}^{-1}$.

The kinetics of the silicon precipitation were studied by the measurement of the lattice parameter of the Al-rich phase (with a precision of 1 part to 40000 ) as a function of ageing time at 397,425 and $448 \mathrm{~K}^{\S}$. The measurement procedure and the heat treatment applied were described earlier [25]. Further, short-time experiments were performed, using a specially designed cylinder to enclose two specimen holders with the very vulnerable specimens. With the new cylinder it was found that ageing temperatures of 397 and $448 \mathrm{~K}$ were reached within one minute.

Crystallite size and microstrain of the aluminium matrix and the silicon precipitates were studied by X-ray diffraction line profile analysis for two liquid quenched AlSi alloys, with $2.6 \mathrm{wt} \%$ $\mathrm{Si}$ and with $13.0 \mathrm{wt} \% \mathrm{Si}$, respectively, as a function of ageing time at $445 \mathrm{~K}$. Sections of the ribbons obtained after melt spinning were placed parallel to each other on a piece of flat glass with the aid of adhesive tape, alternating up- and wheelsides. Thus, the effects that might originate from

\footnotetext{
* This may be due to the collapse of voids during preparation at about room temperature of electron microscope specimens.

In this context it is remarked that according to Rosenbaum and Turnbull [4] silicon precipitates after ageing show a density of the same order of magnitude as the vacancy loop density.

\$Vacancy loops having a diameter of about $10 \mathrm{~nm}$ and a density of about $10^{16} \mathrm{~cm}^{-3}[4,5,22]$ possess an estimated loop line length of $3 \times 10^{4} \mathrm{~cm}^{-2}$.

$\S$ All lattice parameter values presented in this paper are valid at $298 \mathrm{~K}$.
} 
differences between the up- and wheel-side are averaged [26]. After the X-ray investigation the sections were removed from the glass in trichloroethane, followed by cleaning in acetone. Then, the sections were put into a specimen holder which enabled two collections of ribbon sections of different compositions to be aged simultaneously at precisely the same temperature. After heat treatment the ribbon sections were cleaned in trichloroethane, acetone, trichloroethane and acetone in the order given, and then dried.

$\mathrm{X}$-ray diffraction line profiles were recorded using a Siemens $\omega$-diffractometer employing $\mathrm{Cu} K \alpha$ radiation $(45 \mathrm{kV} ; 24 \mathrm{~mA})$. The profiles were recorded by the preset-time method employing steps of $0.02^{\circ} 2 \theta$ and counting times of $100 \mathrm{sec}$. Large portions of the background at both sides of the peak were recorded. The background was interpolated linearly between both extremities, except in the case of the silicon $\{220\}$ reflection were a correction for a tail of the aluminium $\{200\}$ reflection, present in the background, was performed.

The $\{400\}$ and $\{422\}$ line profiles of the Alrich phase were recorded. In the case of $\mathrm{AlSi}$ $13.0 \mathrm{wt} \%$ alloy the $\{111\},\{220\},\{311\}$ and $\{422\}$ profiles of the Si-rich phase were measured as a function of the ageing time. Due to weak intensities these profiles from the AlSi $2.6 \mathrm{wt} \%$ alloy were only measured after $730 \mathrm{~h}$ ageing. The Si-rich phase $\{111\}$ profile from this alloy in the liquid-quenched condition was measured as well, although with a very low accuracy due to the low intensity. The line profiles obtained were analysed using a single-line technique, described elsewhere [27].

\section{Results}

\subsection{Lattice parameters}

\subsubsection{Anomalous effects at initial stages}

Figs. 1 and 2 show the lattice parameter of the Alrich phase as a function of ageing time (times shorter than $120 \mathrm{~min}$ ) for two alloy compositions at the ageing temperatures 399 and $445 \mathrm{~K}$. Two types of anomalous humps are observed in the curves of lattice parameters against ageing time at the start of ageing (the reason of this subdivision is outlined in the discussion (Section 5.3)):

(a) Hump I is observed at the lower ageing temperature, whereas Hump II is observed at the higher ageing temperature.

(b) Hump II is higher than Hump I.

(c) Hump II occurs after longer ageing times than Hump I.

(d) Both effects increase with silicon content (note the different scales of Figs. 1 and 2).

Ribbons obtained by melt spinning generally show local variations of the amount of silicon dissolved in the Al-rich $[2,26]$. This explains differences in the Al-rich phase lattice parameter at the start of ageing and an exact correspondence between the curves of the Al-rich phase lattice parameter against ageing time cannot be expected (Figs. 1 to 4).

\subsubsection{The lattice parameter of the Al-rich phase}

The lattice parameter of the Al-rich phase as a function of ageing time at different temperatures is shown in Figs. 3 and 4 . These results were obtained from Debye-Scherrer photographs by Nelson-Riley extrapolation [28]. As shown for the first time in [25], a difference in thermal

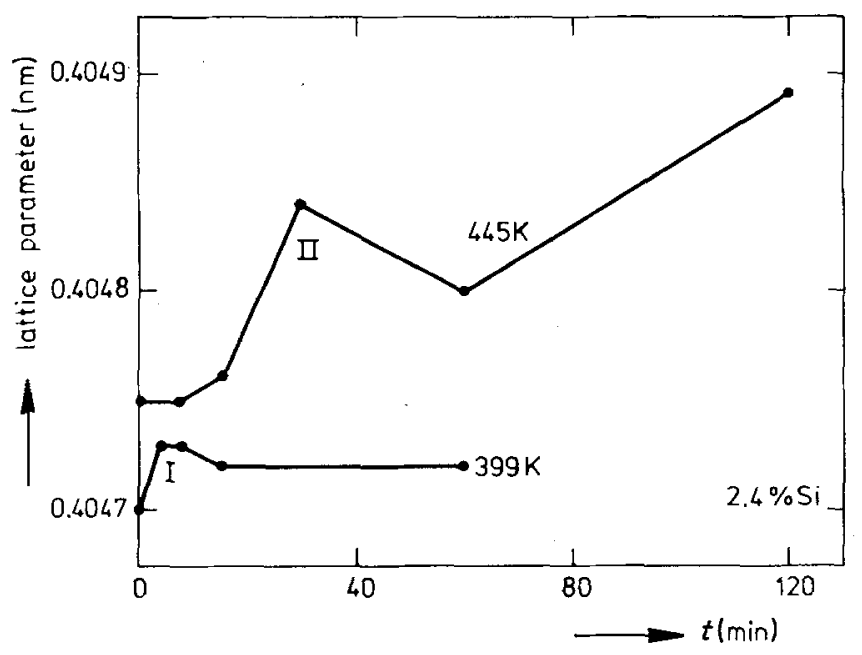

Figure 1 The lattice parameter of the A1-rich phase in the AlSi $2.4 \mathrm{wt} \%$ alloy after short times of ageing. 


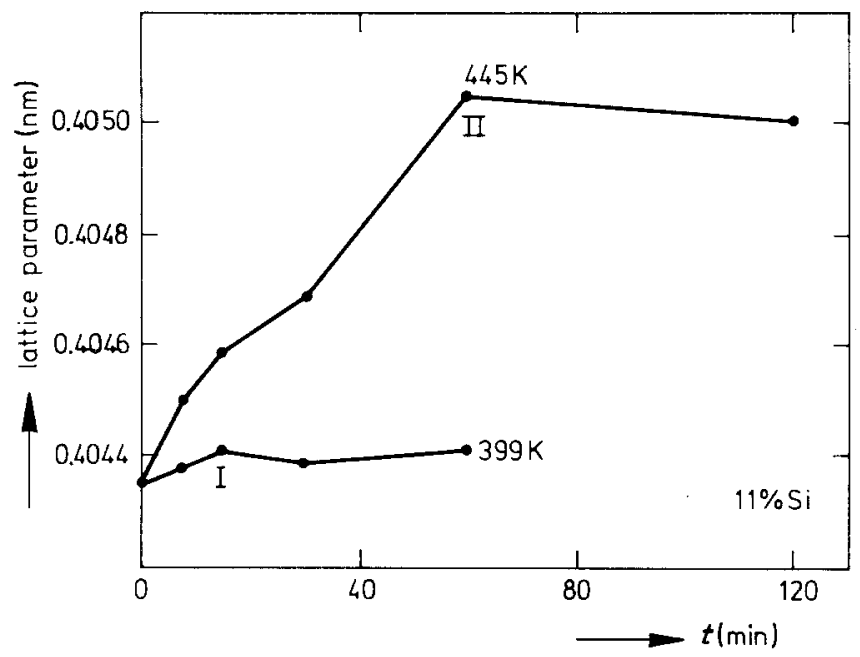

Figure 2 The lattice parameter of the Al-rich phase in the AlSi $11.0 \mathrm{wt} \%$ alloy after short times of ageing.

expansion between two phases in a system can cause macrostrains. A correction for this effect can be performed (see Section 5.1). Resulting curves for the Al-rich phase lattice parameter against ageing time are presented by dash-dot lines in Figs. 3 and 4.

\subsubsection{The lattice parameter of the Si-rich phase}

Because of the small amount of silicon, present in the hypo-eutectic alloys of this investigation, the determination of the Si-rich phase lattice parameter by applying a Nelson-Riley procedure [28] was impossible. In these cases the Si-rich phase lattice parameter was studied as a function of ageing time and temperature by measuring a selected reflection on a Debye-Scherrer photograph; precision was improved by a tenfold measurement of the line. In Table I the results are shown. The comparison of results from different reflections is justified in view of the zero slope of the Nelson-
Riley plot obtained for hypereutectic alloys. The following observations can be made:

(a) The value of the Si-rich phase lattice parameter after ageing is smaller than after liquid quenching, and is also smaller than the equilibrium value of silicon $(0.54307 \mathrm{~nm}$; [29]).

(b) The silicon lattice parameter after completed precipitation decreases with increasing ageing temperature (this trend is best seen from the results for the AlSi $11.0 \mathrm{wt} \%$ alloy; these data were taken from high angle reflections).

In addition, for the hypereutectic alloys $\mathrm{AlSi}$ $22.4 \mathrm{wt} \%$ and AlSi 34.8 wt \% the Si-rich phase lattice parameter was investigated (now by Nelson-Riley extrapolation [28]) before and after ageing at $445 \mathrm{~K}$. In Table I these results are gathered too. The following observations can be made:

(c) In the hypereutectic alloys the Si-rich phase lattice parameter is considerably larger than in the hypo-eutectic alloys.

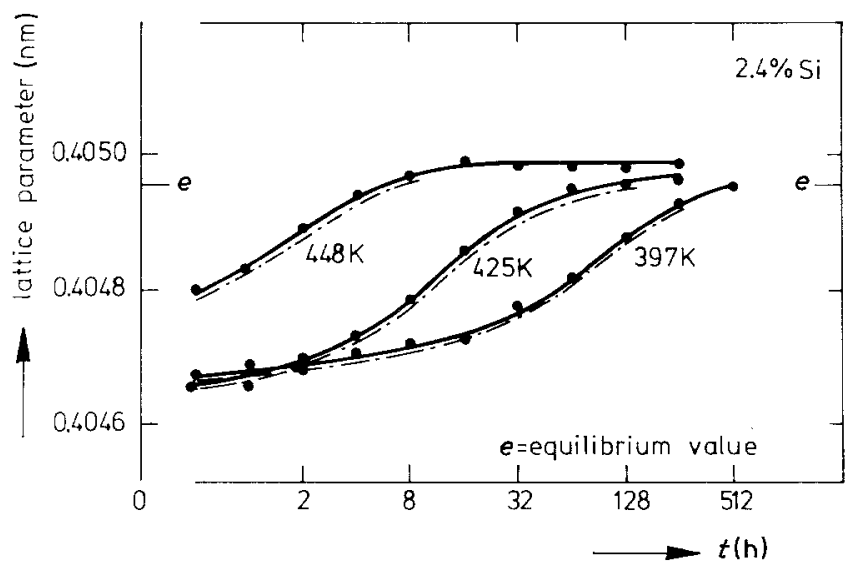

Figure 3 The lattice parameter of the Al-rich phase in the AlSi $2.4 \mathrm{wt} \%$ alloy as a function of ageing time; dash-dot lines indicate the results obtained after correction for the difference in thermal expansion between the Al-rich and Si-rich phase (cf. Section 5.1). The equilibrium value is indicated too. 


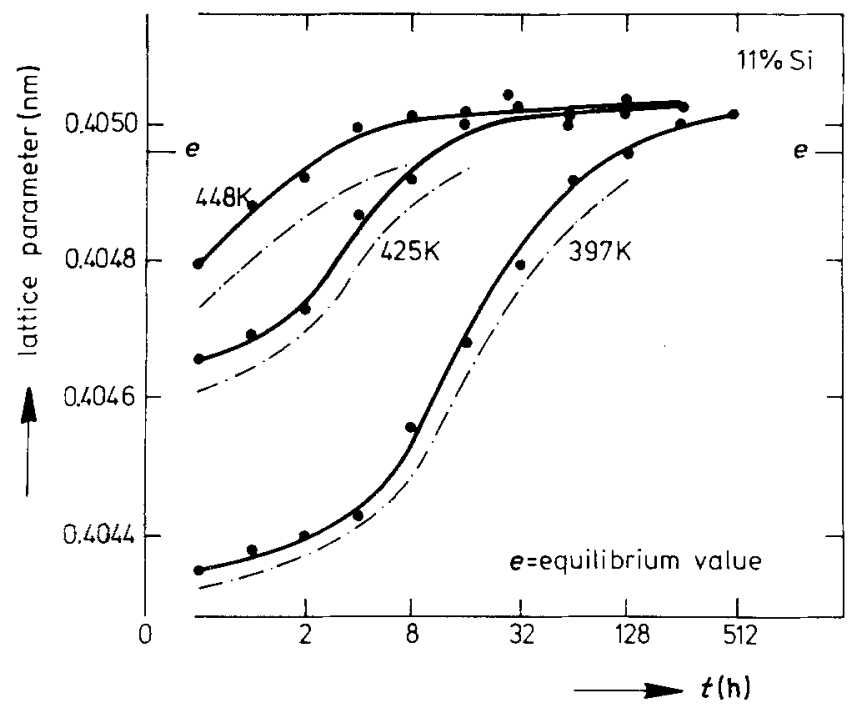

Figure 4 The lattice parameter of the Al-rich phase in the AlSi $11.0 \mathrm{wt} \%$ alloy as a function of ageing time; dash-dot lines indicate the results obtained after correction for the difference in thermal expansion between the Al-rich and Si-rich phase (cf. Section 5.1). The equilibrium value is indicated too.

(d) In agreement with the hypo-utectic alloys the value of the Si-rich phase lattice parameter after ageing is smaller than after liquid quenching, but in contrast with the hypo-eutectic alloys the silicon lattice parameter remains after $128 \mathrm{~h}$ ageing larger than the equilibrium value.

\subsection{Crystallite sizes and lattice strains}

$\mathrm{X}$-ray diffraction line broadening is caused by instrumental aberrations, the wavelength distribution and the structural defects in the specimen. The broadening by instrumental aberrations and by the wavelength distribution can be determined by measuring corresponding line profiles of appropriate standard specimens. In this paper it is assumed that the profiles of both the specimen to be investigated and the standard specimen can be described by a Voigt function [27]. A Voigt func- tion is the outcome of the folding of Cauchy and Gaussian components. In practice it is often considered that size broadening results in Cauchyshaped profiles and that strain broadening results in Gaussian-shaped profiles [27, 28, 30].

The crystallite size and the microstrain were followed as a function of ageing time at $445 \mathrm{~K}$. The results have been collected in Figs. 5 to 8 and in Table II. For the aluminium matrix the following observations can be made:

(a) For the AlSi $2.6 \mathrm{wt} \%$ the line broadening is almost entirely of Gaussian shape. For the AlSi 13.0 wt \% alloy the Gaussian component dominates strongly.

(b) Interpreting the total line broadening for both alloys as due to microstrains it is found that the microstrain decreases with increasing ageing time. The microstrains in a [100] direction are

TAB LE IA The lattice parameter of the Si-rich phase in hypo-eutectic alloys

\begin{tabular}{|c|c|c|c|c|c|}
\hline \multirow{2}{*}{$\begin{array}{l}\text { Alloy } \\
\text { (wt \% Si) }\end{array}$} & \multirow{2}{*}{$\begin{array}{l}\text { Selected } \\
\text { reflection } \\
\Sigma H^{2}\end{array}$} & \multirow{2}{*}{$\begin{array}{l}\text { After } \\
\text { liquid quenching } \\
{ }^{a} \mathrm{Si}(\mathrm{nm})\end{array}$} & \multicolumn{3}{|c|}{ After ageing } \\
\hline & & & $\begin{array}{l}\text { Time } \\
\text { (h) }\end{array}$ & $\begin{array}{l}\text { Temperature } \\
(\mathrm{K})\end{array}$ & $\begin{array}{l}{ }^{a} \mathrm{Si} \\
(\mathrm{nm})\end{array}$ \\
\hline \multirow{3}{*}{2.4} & 11 & $0.5432( \pm 5)$ & 256 & $397 \pm 3$ & $0.5429( \pm 2)$ \\
\hline & 8 & $0.5431( \pm 2)$ & 256 & $425 \pm 4$ & $0.5425( \pm 2)$ \\
\hline & 11 & $0.5435( \pm 2)$ & 256 & $448 \pm 5$ & $0.5428( \pm 1)$ \\
\hline \multirow{3}{*}{11.0} & 11 & $0.5430( \pm 4)$ & 256 & $397 \pm 3$ & $0.5429( \pm 1)$ \\
\hline & 24 & $0.5428( \pm 2)$ & 256 & $425 \pm 4$ & $0.5427( \pm 1)$ \\
\hline & 24 & $0.5429( \pm 1)$ & 256 & $448 \pm 5$ & $0.5426( \pm 1)$ \\
\hline \multicolumn{6}{|c|}{ TAB LE IB The lattice parameter of the Si-rich phase in hypereutectic alloys } \\
\hline 22.4 & NR* & $0.54395( \pm 9)$ & 128 & $445 \pm 2$ & $0.5437( \pm 2)$ \\
\hline 34.8 & NR & $0.5444( \pm 2)$ & 128 & $445 \pm 2$ & $0.5437( \pm 2)$ \\
\hline
\end{tabular}

*NR $=$ Nelson - Riley extrapolation. 


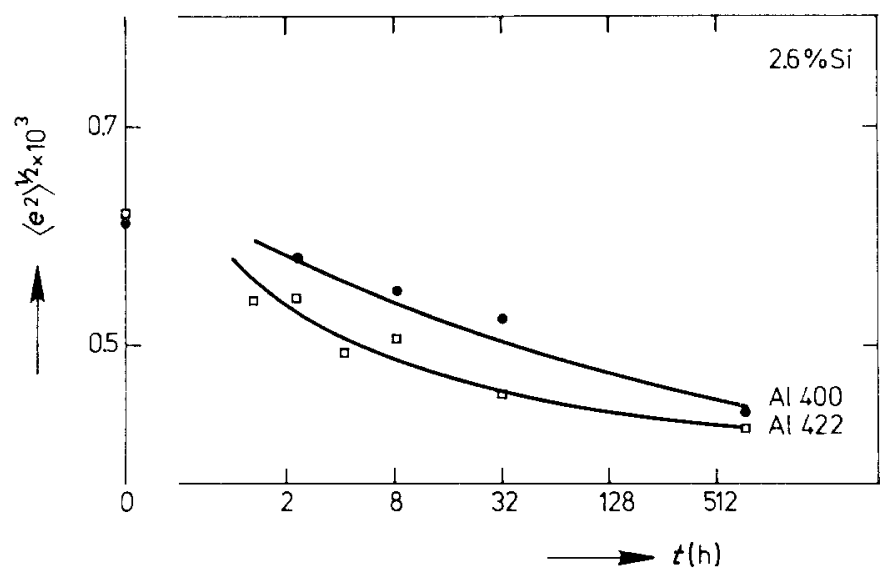

Figure 5 The microstrain, $\left\langle e^{2}\right\rangle^{1 / 2}$, of the Al-rich phase in the AlSi $2.6 \mathrm{wt} \%$ alloy as a function of time of ageing at $445 \mathrm{~K}$.

larger than in a [211] direction, especially for the AlSi 13.0 wt \% alloy (cf. Figs. 5 and 6).

Due to the weak intensities observed for the Sirich phase, an appreciable scatter is present on the size-strain values for the Si-rich phase as derived from the Cauchy and Gaussian components, respectively. The best results are, of course, obtained after completed precipitation. Nevertheless, for the $\mathrm{Si}$-rich phase the following observations can be made:

(c) The crystallite size of the Si-rich precipitates increases with ageing time. The domain size in a [111] direction is in general smaller than in [220], [3 111$]$ and [2 111 ] directions.

(d) In case of the AlSi $13.0 \mathrm{wt} \%$ alloy, in particular the microstrain in a [1 11] direction shows an anomalous behaviour: first a decrease, than an increase; at last followed by a continuous decrease in the coarsening stage (Fig. 7). After $730 \mathrm{~h}$ ageing the microstrain in the Si-rich precipitates of the

AlSi $13.0 \mathrm{wt} \%$ alloy is smaller than in the Si-rich precipitates of the AlSi $2.6 \mathrm{wt} \%$ alloys (Table II).

\section{Discussion}

\subsection{The correction of the Al-rich phase lattice parameter for the effect caused by the difference in thermal expansion between the Al-rich phase and the Si-rich phase}

From the value of the Al-rich phase lattice parameter the amount of silicon dissolved can be calculated. For this, normally a Végard-type equation is used. However, as shown earlier [25] a difference in thermal expansion between two phases in a specimen. can also change the average lattice parameter of the matrix after annealing. The total difference, $\Delta a$, between the measured lattice parameter of the Al-rich phase, $a_{\mathrm{m}}$, and the lattice parameter of pure aluminium $a_{\mathrm{Al}}$ can be written as [25]:

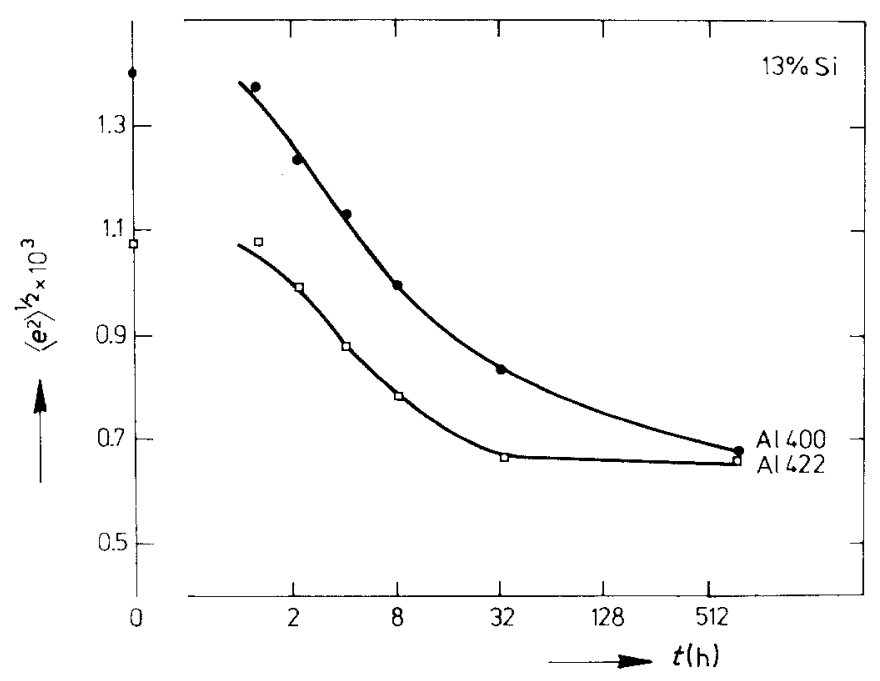

Figure 6 The microstrain, $\left\langle e^{2}\right\rangle^{1 / 2}$, of the Al-rich phase in the AlSi $13.0 \mathrm{wt} \%$ alloy as a function of time of ageing at $445 \mathrm{~K}$. 


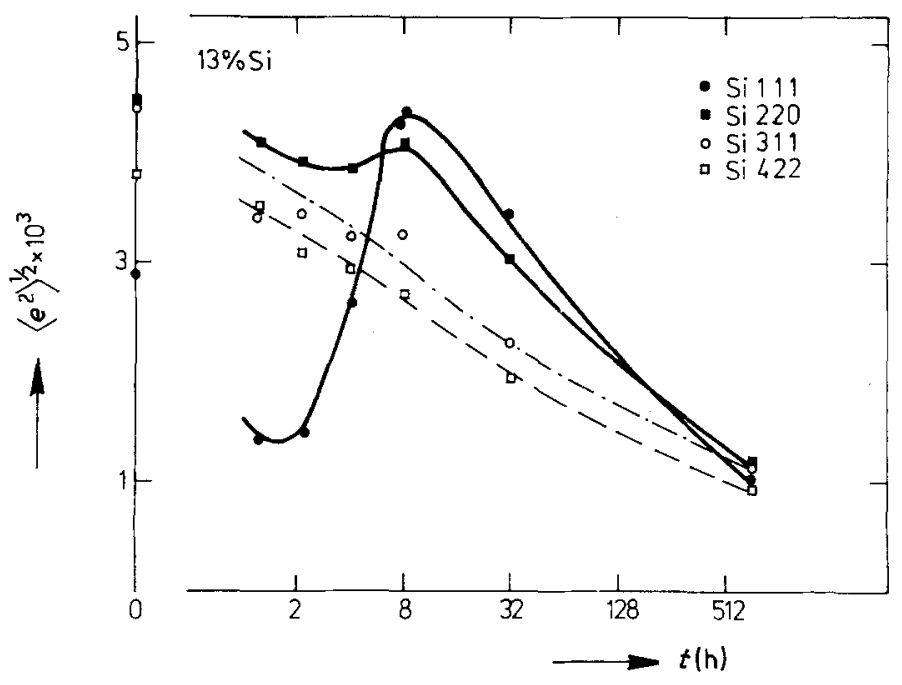

Figure 7 The microstrain, $\left\langle e^{2}\right\rangle^{1 / 2}$, of the Si-rich phase in the AlSi 13.0 $\mathrm{wt} \%$ alloy as a function of time of ageing at $445 \mathrm{~K}$.

$$
\Delta a \equiv a_{\mathrm{m}}-a_{\mathrm{Al}}=f_{\mathrm{s}}\left(x_{\mathrm{Si}}\right)+f_{\mathrm{T}}\left(y_{\mathrm{Si}}\right)
$$

where the change of the average lattice parameter due to an atomic fraction of silicon dissolved in the Al-rich phase, $x_{\mathrm{Si}}$, is represented by $f_{\mathrm{s}}\left(x_{\mathrm{Si}}\right)$ and the change of the average lattice parameter due to the difference in thermal expansion between the dispersed Si-rich phase (with a volume fraction of $\left.y_{\mathrm{Si}}\right)$ and the aluminium matrix is given by $f_{\mathrm{T}}\left(y_{\mathrm{Si}}\right)$.

The term $f_{\mathrm{s}}\left(x_{\mathrm{Si}}\right)$ follows from experimental data. Often $f_{\mathrm{s}}\left(x_{\mathrm{Si}}\right)$ can be approximated by $p x_{\mathrm{Si}}$ (Végard), where $p$ is a constant. The term $f_{\mathrm{T}}\left(y_{\mathrm{Si}}\right)$ can be written as $q y_{\mathrm{Si}}$, where $q$ follows from experimental data [25]. According to [25] the values of $p$ and $q$ are, respectively:

$$
\begin{aligned}
& p=-1.74 \times 10^{-2}(\mathrm{~nm}) \\
& q=3.73 \times 10^{-6} \Delta T(\mathrm{~nm})
\end{aligned}
$$

with $\Delta T=T_{\text {ageing }}-T_{\text {room }}$.

However, it should be realized, that the proportionality constant $p$ was obtained from solidquenched specimens [31]. In fact it incorporates contributions due to dissolved silicon atoms and to quenched-in vacancies. Contributions to the lattice parameter due to silicon atoms dissolved and to quenched-in vacancies may be in different proportion after liquid quenching as compared to solid quenching. Hence, use of the above mentioned value of $p$ in this work may.introduce uncertainties in calculated values of $x_{\mathrm{Si}}$.

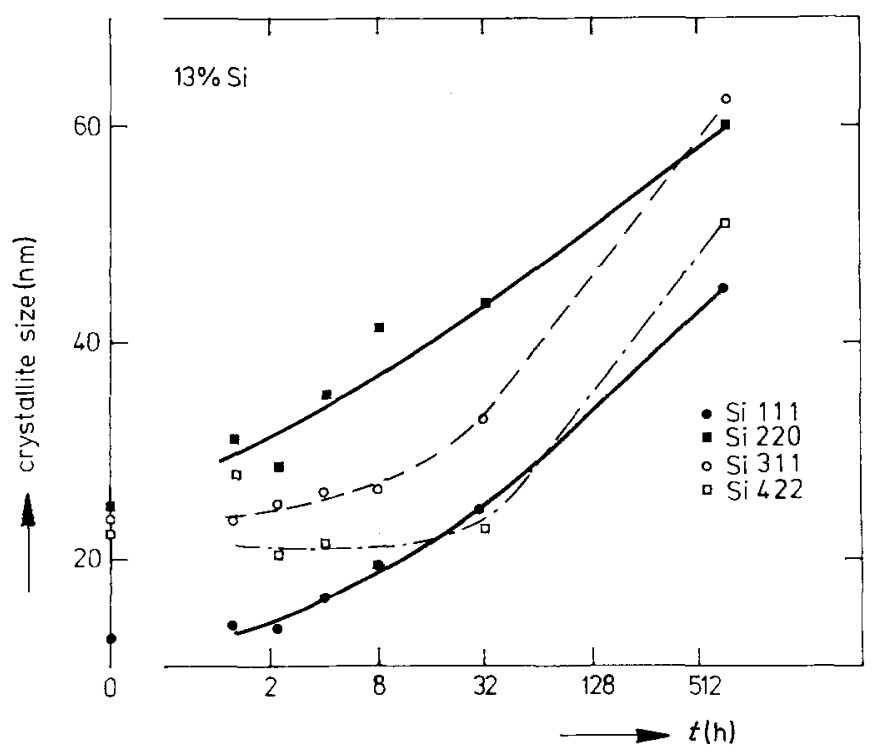

Figure 8 The crystallite size, $D_{\mathrm{eff}}$, of the Si-rich phase in the AISi 13.0 wt $\%$ alloy as a function of time of ageing at $445 \mathrm{~K}$. 
T AB LE II Microstrain values, $\left\langle e^{2}\right\rangle^{1 / 2}$, of the Al-rich and Si-rich phases after $730 \mathrm{~h}$ ageing at $445 \mathrm{~K}$

\begin{tabular}{lllllll}
\hline & Reflection & & & \\
\cline { 2 - 6 } & $\mathrm{Al}\{400\}$ & $\mathrm{Al}\{422\}$ & $\mathrm{Si}\{111\}$ & $\mathrm{Si}\{220\}$ & $\mathrm{Si}\{311\}$ & $\mathrm{Si}\{422\}$ \\
$\begin{array}{l}\text { Silicon content } \\
\text { (wt } \%)\end{array}$ & $\left(\times 10^{3}\right)$ & $\left(\times 10^{3}\right)$ & $\left(\times 10^{3}\right)$ & $\left(\times 10^{3}\right)$ & $\left(\times 10^{3}\right)$ & $\left(\times 10^{3}\right)$ \\
\hline 2.6 & 0.44 & 0.43 & 1.4 & 2.9 & 2.7 & 2.0 \\
13.0 & 0.68 & 0.67 & 1.0 & 1.2 & 1.1 & 1.0 \\
\hline
\end{tabular}

With the aid of Equation A2 (see Appendix) $x_{\mathrm{Si}}$ can be calculated from Equation 1. The values of the lattice parameter corrected for thermal strains, $a_{\text {cor }}=a_{\mathrm{Al}}+p x_{\mathrm{Si}}$, are presented by dash-dot lines in Figs. 3 and 4.

\subsection{The composition of the aluminium matrix after liquid quenching}

For the study of precipitation kinetics (see Section 5.4) knowledge of $x_{\mathrm{Si}}$ after liquid quenching is required. This value of $x_{\mathrm{Si}}$ might be obtained from the lattice parameter as measured after liquid quenching. However, a correction of the lattice parameter for the effect to thermal strains cannot be performed at the start of ageing, since the solidification temperature and thus $\Delta T$ (see Section $5.1)$ is unknown. Therefore, the value of $x_{\mathrm{Si}}$ at $t=0$ was determined by extrapolation of $x_{\mathrm{Si}}$ against ageing time $t$ to $t=0$ (Table III). This extrapolation procedure is accompanied by some uncertainties. Firstly, the effects due to Humps I and II can be accounted for by an educated guess only. Secondly, the rate of the precipitation process at the highest ageing temperature is higher than at the lowest temperature. Therefore, extrapolation down to $t=0$ from the plot $x_{\mathrm{Si}}$ against ageing time is much more reliable for the lowest ageing temperature than for the highest one.

Inspection of the values of $x_{\mathrm{Si}}$ at $t=0$, obtained from the above extrapolation, in terms of the corresponding Al-rich phase lattice parameters shows (Table III), that in most cases the measured lattice parameters are lower than the extrapolated ones (see also Figs. 1 and 2). This "finding may be understood as follows: the ribbons after liquid quenching possess a high excess vacancy concentration. Excess vacancies lower the lattice parameter.

\subsection{The behaviour of the Al-rich phase lattice parameter during initial stages of ageing}

\subsubsection{Hump I}

The increase of the Al-rich phase lattice parameter at the very start of ageing at $399 \mathrm{~K}$ (Figs. 1 and 2) can be attributed to the annihilation of excess vacancies (e.g. at sinks and by the creation of vacancy loops; Section 2). This assertion is made plausibly below.

The lattice parameter of a "binary" alloy of pure aluminium and vacancies may be written as:

$$
a=c_{\mathrm{v}} a_{\mathrm{v}}+\left(1-c_{\mathrm{v}}\right) a_{\mathrm{Al}}
$$

where $a$ is the lattice parameter of the alloy, $a_{\mathrm{v}}$ is the fictitious vacancy lattice parameter and $c_{\mathrm{v}}$ is the fraction of atomic sites occupied by vacancies.

Suppose, the volume of a vacancy is half of the volume of the aluminium atom [32], then $a_{v}$ can be written as:

$$
a_{\mathrm{v}}=2^{-1 / 3} a_{\mathrm{Al}} .
$$

From Equations 2 and 3, the change of the alu-

\begin{tabular}{|c|c|c|c|c|}
\hline \multirow{2}{*}{$\begin{array}{l}\text { Alloy } \\
\text { (wt \% Si) }\end{array}$} & \multirow{2}{*}{$\begin{array}{l}\text { Ageing } \\
\text { temperature } \\
\text { (K) }\end{array}$} & \multirow{2}{*}{$\begin{array}{l}x_{\mathrm{Si}} \times 10^{2} \\
\text { extrapolated }\end{array}$} & \multicolumn{2}{|c|}{ Lattice parameter } \\
\hline & & & $\begin{array}{l}\text { Extrapolated } \\
(\mathrm{nm})\end{array}$ & $\begin{array}{l}\text { Measured } \\
(\mathrm{nm})\end{array}$ \\
\hline 2.4 & $\begin{array}{l}397 \pm 3 \\
425 \pm 4 \\
448 \pm 5\end{array}$ & $\begin{array}{l}1.67 \\
1.75 \\
1.17\end{array}$ & $\begin{array}{l}0.40467 \\
0.40466 \\
0.40476\end{array}$ & $\begin{array}{l}0.40468 \\
0.40461 \\
0.40470\end{array}$ \\
\hline 11.0 & $\left\{\begin{array}{l}397 \pm 3 \\
425 \pm 4 \\
448 \pm 5\end{array}\right.$ & $\begin{array}{l}3.81 \\
2.18 \\
1.9\end{array}$ & $\begin{array}{l}0.40430 \\
0.40458 \\
0.40463\end{array}$ & $\begin{array}{l}0.40427 \\
0.40453 \\
0.40464\end{array}$ \\
\hline
\end{tabular}

TABLE III The lattice parameter of the Al-rich phase after liquid quenching 
minium lattice parameter $\Delta a_{\mathrm{v}}$ due to a change of the excess vacancy concentration $\Delta c_{\mathrm{v}}$ can be written as:

$$
\Delta a_{\mathrm{v}}=\left(2^{-1 / 3}-1\right) a_{\mathrm{Al}} \Delta c_{\mathrm{v}} .
$$

In case Hump I is attributed to the annihilation of excess vacancies, then for both alloys the change of the excess vacancy concentration may be estimated from the respective heights of Hump I by using Equation 4 (cf. Figs. 1 and 2):

AlSi 2.4 wt \%:

$$
\begin{aligned}
\Delta a(\text { Hump I }) & =(0.3 \pm 0.2) \times 10^{-4}(\mathrm{~nm}) \\
\Delta c_{\mathrm{v}} & =-(3.6 \pm 2.4) \times 10^{-4} .
\end{aligned}
$$

AlSi $11.0 \mathrm{wt} \%$ :

$$
\begin{aligned}
\Delta a(\text { Hump I }) & =(0.5 \pm 0.2) \times 10^{-4}(\mathrm{~nm}) \\
\Delta c_{\mathrm{v}} & =-(6.0 \pm 2.4) \times 10^{-4} .
\end{aligned}
$$

Due to the strong interaction between silicon and vacancies a large fraction of the excess vacancies will be bound to silicon atoms dissolved after quenching (cf. Section 2). However, a small fraction of "free" excess vacancies will exist. The concentrations of free and bound excess vacancies differ by an order of magnitude [22]. Obviously, the concentration of the "free" vacancies, $c_{\mathrm{v}}^{\mathrm{Al}}$, will depend on the silicon content of the aluminiumrich phase. $c_{\mathrm{v}}^{\mathrm{Al}}$ may be estimated by (cf. [21]):

$$
c_{\mathrm{v}}^{\mathrm{Al}}=\left(1-x_{\mathrm{Si}}\right)^{z} A \exp \left(-E_{\mathrm{f}} / k T\right)
$$

where $z$ is the coordination number (for $\mathrm{fcc}$ $z=12$ ). The pre-exponential factor $A$ and the vacancy formation energy $E_{\mathrm{f}}$ have been taken from [33]. The temperature $T$ was taken equal to the appropriate melting temperature. With $x_{\mathrm{Si}}=$ $1.41 \times 10^{-2}$ and $x_{\mathrm{Si}}=3.53 \times 10^{-2}$ for the AlSi $2.4 \mathrm{wt} \%$ and the AlSi $11.0 \mathrm{wt} \%$, respectively, as obtained after extrapolation to $t=0$, one obtains

$$
\begin{aligned}
\text { AlSi } 2.4 \mathrm{wt} \%: c_{\mathrm{v}}^{\mathrm{Al}} & =5.4 \times 10^{-4} \\
\text { AlSi } 11.0 \mathrm{wt} \%: c_{\mathrm{v}}^{\mathrm{Al}} & =2.3 \times 10^{-4} .
\end{aligned}
$$

These values of free excess vacancy concentration $c_{\mathbf{v}}^{\mathrm{Al}}$ are of the same order of magnitude as the change of excess vacancy concentration calculated above from the heights of Hump I in Figs. 1 and 2. It might be argued that the loss of "free" excess vacancies is suppleted by excess vacancies bound to (clusters of) dissolved silicon atoms. For kinetic reasons this process is unlikely to occur substantially at the start of ageing, as has been found for other aluminium alloys in [11] (this is also supported by the present investigation; see Section 5.4). Thus, one is tempted to conclude that the rise of the Al-rich phase lattice parameter at the start of ageing can be attributed to the annihilation of "free" excess vacancies. Considering this in more detail, the experimental $\Delta c_{\mathrm{v}}$ seems larger for the AlSi $11.0 \mathrm{wt} \%$ alloy than for the AlSi $2.4 \mathrm{wt} \%$ alloy, whereas theoretically a reverse trend is suggested. However, in view of the experimental errors and the uncertainties inherent to the theoretical calculation (Equation 5) and to the choice of its parameters detailed conclusions are unjustified.

The lowering of the lattice parameter after Hump I may be caused by the relaxation of quenching stresses. The occurrence of stress of this kind has been demonstrated earlier for solidquenched aluminium alloys [34-36].

Annihilation of the free excess vacancies proceeds by diffusion. The diffusion constant for vacancy migration can be written as

$$
D=D_{0} \exp \left(-E_{\mathrm{m}} / k T\right),
$$

with $E_{\mathrm{m}}$ as the migration energy for a vacancy. Substituting $E_{\mathrm{m}}=0.65 \mathrm{eV}$ [18] it follows that the vacancy diffusion constant at $445 \mathrm{~K}$ is seven times greater than at $399 \mathrm{~K}$. Therefore, as compared to Hump I, Hump II observed at the highest ageing temperature at larger ageing times will have another origin.

\subsubsection{Hump //}

In our opinion a similar phenomenon to Hump II (Figs. 1 and 2) was observed by Itagaki et al. [1]. It was suggested that the transformation stresses induced by the silicon precipitation were not readily dissipated by the accompanying recovery process. At a lower ageing temperature this effect can be smaller, even undetectable, since the precipitation proceeds more slowly. This can explain the absence of Hump II at the lowest ageing temperature. It can be expected that Hump II will be larger the more silicon has been dissolved in the Al-rich phase in the as-liquid-quenched condition, which agrees with the experimental finding (note the difference in scale between Figs. 1 and 2). As precipitation proceeds, per unit of time less transformation strain is introduced because less silicon precipitates and the recovery process can catch up the strains induced. This explains why a 
lowering of the Al-rich phase lattice parameter after Hump II occurs (cf. Figs. 1 and 2).

\subsection{The precipitation of silicon from the supersaturated Al-rich phase after liquid quenching}

For the study of the kinetics of precipitation a parameter $X_{\mathrm{t}}$ (the fraction transformed) is defined by:

$$
X_{\mathrm{t}}=\left(c_{0}-c_{\mathrm{t}}\right) /\left(c_{0}-c_{\mathrm{e}}\right)
$$

where $c_{0}$ is the silicon concentration in the Al-rich phase at time $t=0, c_{\mathrm{e}}$ is the equilibrium concentration of silicon in the Al-rich phase per unit volume and $c_{t}$ is the silicon concentration in the Alrich phase after ageing time $t$.

At the commonly applied ageing temperatures for the AlSi alloys $c_{\mathrm{e}} \simeq 0$ [37]. Using atomic fractions, Equation 6 transforms into:

$$
1-X_{\mathrm{t}}=\left(a_{0}^{3} x_{\mathrm{Si}}^{t=t}\right) /\left(a_{\mathrm{m}}^{3} x_{\mathrm{Si}}^{t=0}\right)
$$

where $a_{0}$ is the Al-rich phase lattice parameter measured at $t=0, a_{\mathrm{m}}$ is the Al-rich phase lattice parameter after ageing time $t, x_{\mathrm{Si}}^{t=0}$ and $x_{\mathrm{Si}}^{t=t}$ are the atomic fraction of silicon in solid solution in the Al-rich phase at time $t=0$ and $t=t$, respectively. The values of $x_{\mathrm{Si}}^{t=t}$ and $x_{\mathrm{Si}}^{t=0}$ are obtained as described in Sections 5.1, 5.2 and the Appendix. The resulting $\left(1-X_{t}\right)$-curves are plotted in Figs. 9 and 10 .

Assuming that the precipitation process proceeds in the same manner at the three ageing tem-

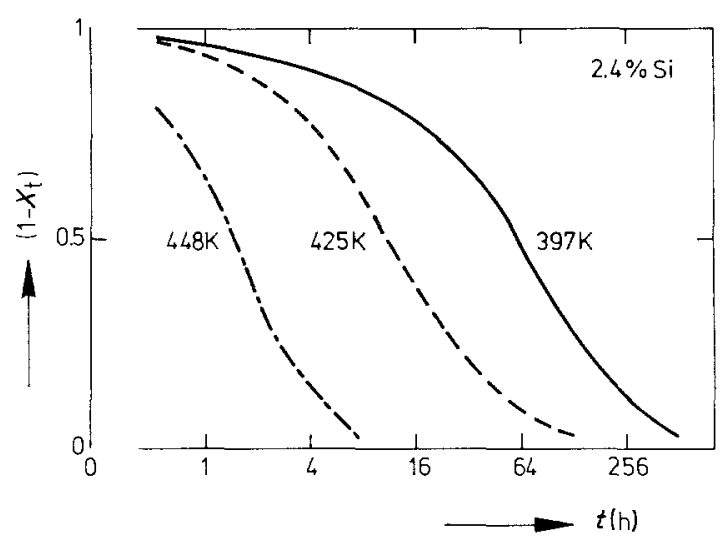

Figure 9 The reaction parameter, $\left(1-X_{t}\right)$, for the precipitation on the AlSi 2.4 wt \% alloy as a function of ageing time.

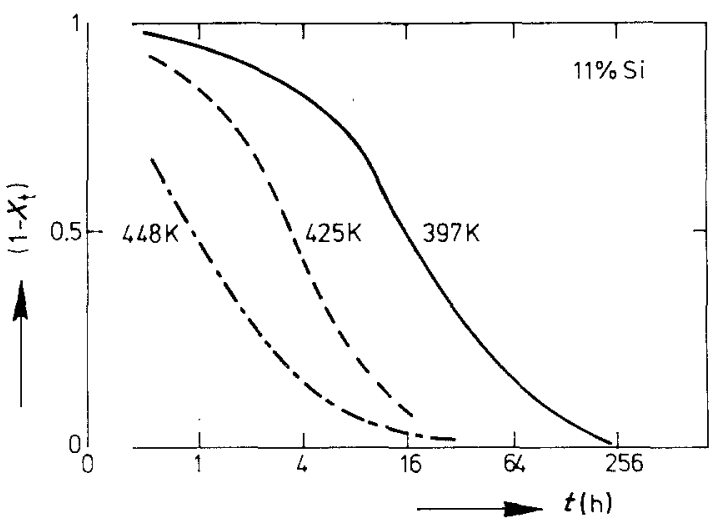

Figure 10 The reaction parameter, $\left(1-X_{t}\right)$, for the precipitation in the A1Si $11.0 \mathrm{wt} \%$ alloy as a function of ageing time.

peratures applied, the activation energy can be calculated by plotting the time needed to reach a certain value of $\left(1-X_{\mathrm{t}}\right)$ against the reciprocal temperature. The results for progressive values of $X_{\mathrm{t}}$ are gathered in Table IV. (The values of $X_{\mathrm{t}}$ chosen were not affected by Hump I and/or Hump II). Notwithstanding inaccuracies inherent in the approximations made in the procedures followed, it may be concluded that the values of the activation energy for precipitation

(a) are smaller than the value reported for precipitation of silicon in solid-quenched AlSi alloys (i.e. $1.27 \pm 0.03 \mathrm{eV}$; [8]);

(b) increase as the precipitation process proceeds.

In the following discussion it is assumed that the dominant step in the precipitation process is the diffusion of silicon atoms in the Al-rich phase*.

The activation energy for the diffusion of silicon in aluminium at thermal equilibrium corresponds

TABLE IV The activation energy $E_{\mathrm{A}}$ for silicon precipi-

\begin{tabular}{|c|c|c|}
\hline Alloy & $1-X_{t}$ & $E_{\mathrm{A}}(\mathrm{eV})$ \\
\hline \multirow{4}{*}{ AlSi $2.4 \mathrm{wt} \%$} & $0 . \overline{8}$ & 0.9 \\
\hline & 0.6 & 1.1 \\
\hline & 0.4 & 1.1 \\
\hline & 0.2 & 1.2 \\
\hline \multirow{3}{*}{ AlSi $13.0 \mathrm{wt} \%$} & 0.6 & 0.8 \\
\hline & 0.4 & 0.9 \\
\hline & 0.2 & 0.9 \\
\hline
\end{tabular}
tation at constant values of $\left(1-X_{\mathrm{t}}\right)$

*The progress of precipitation can be described only approximately by the Avrami equation $\left(1-X_{t}=\exp (-k t)^{n}\right)$. Best fitting can be expected for the first stage of precipitation [38]. From our experimental results values of the time constant $n$ in the range 0.7 to 1.1 are obtained. From the review given in [38] it may be concluded that the obtained values of $n$ indicate diffusion-controlled growth, which supports the assumptions made. 
to $1.32 \mathrm{eV}[37,39]$. Therefore, it can be concluded that the activation energy of precipitation in solid-quenched AlSi alloys, as determined by Köster and Knorr [8] at a late stage of precipitation, corresponds to the diffusion of silicon in aluminium in the presence of the thermal equilibrium concentration of vacancies.

For a quenched AlSi specimen of a certain composition the same excess vacancy concentration will be present at the start of precipitation at each of the ageing temperatures applied. Hence, the energy of formation of a vacancy is absent in the activation energy for silicon diffusion and the activation energy at the start of precipitation will be given by the activation energy of migration of a vacancy (neglecting the temperature dependence of the correlation factor [40]). As the precipitation process proceeds, the excess vacancies associated with silicon are annealed out gradually (see Section 2) and thus at different ageing temperatures different vacancy concentrations will be present. This effect enhances the activation energy for precipitation, which corresponds with the experimental findings (at the end of the precipitation the activation energy equals the sum of $E_{\mathrm{f}}$ and $\left.E_{\mathrm{m}}\right)$.

A larger supersaturation with respect to excess vacancies and dissolved silicon will enhance the precipitation kinetics. For the AlSi $11.0 \mathrm{wt} \%$ alloy the amounts of excess vacancies and of dissolved silicon are larger than for the AlSi $2.4 \mathrm{wt} \%$ alloy. Indeed, precipitation in the AlSi $11.0 \mathrm{wt} \%$ alloy proceeds faster than in the AlSi $2.4 \mathrm{wt} \%$ alloy (cf. Figs. 9 and 10).

Further, assuming that on ageing the fractional decrease of the excess vacancy concentration is approximately the same for both alloys, it can be expected that at the same $X_{\mathbf{t}}$ the activation energy for precipitation in the AlSi $11.0 \mathrm{wt} \%$ will be smaller (see discussion above) than in the AlSi $2.4 \mathrm{wt} \%$ alloy, as is observed.

\subsection{The precipitation of aluminium from the supersaturated $\mathrm{Si}$-rich phase after liquid quenching}

The equilibrium solid solubility of aluminium in silicon is uncertain $[37,41]$. According to
Wamich's data [41] the dissolution of aluminium in silicon enlarges the lattice parameter of the $\mathrm{Si}$ rich phase. Thus, the decrease of this lattice parameter observed on ageing (see Table I) may be interpreted as a result of the precipitation of aluminium from the Si-rich phase*.

In the hypo-eutectic alloys the Al-rich phase solidifies primarily, whereas in the hypereutectic alloys the Si-rich phase solidifies primarily. According to the phase diagram [37] it may be expected that, after liquid quenching, the Si-rich phase of the hypereutectic alloys contains more aluminium (retrograde solidus) than the Si-rich phase of the hypo-eutectic alloys. Indeed, the value of the Si-rich phase lattice parameter after liquid quenching is significantly larger for the hypereutectic, than for the hypo-eutectic alloys (see Table I).

\subsection{Unusual lattice parameters of the Si-rich phase after completed precipitation}

After $256 \mathrm{~h}$ ageing at the three ageing temperatures applied the lattice parameter of the Si-rich phase in the hypo-eutectic alloys is smaller than the lat tice parameter of pure silicon ${ }^{\dagger}$. This may be caused by the difference in thermal expansion between the Al-and Si-rich phases. As discussed in Section 5.1 the same effect caused an increase of the Al-rich phase lattice parameter after complete precipitation. Analogously, a decrease of the Si-rich phase lattice parameter as compared to the lattice parameter of pure silicon can be expected, as is observed (cf. Table I).

According to Eshelby's theory on point imperfections $[25,38,42]$ the volume change of a misfitting spherical inclusion depends on its radius and on the elastic constants of the inclusion and of the surrounding matrix. For a spherical inclusion of phase $\mathrm{B}$ (silicon) in a continuous matrix of phase A (aluminium), the misfit parameter $\epsilon$ is defined by

$$
\epsilon=\left(r_{0}^{\mathrm{B}}-r_{0}^{\mathrm{A}}\right) / r_{0}^{\mathrm{A}}
$$

where $r_{0}^{\mathrm{B}}$ and $r_{0}^{\mathrm{A}}$ are the radii of the "free" undeformed inclusion $B$ and of the empty undeformed cavity in the matrix A, respectively. Assuming

*The amount of aluminium dissolved, as estimated from the decrease of the Si-rich phase lattice parameter using Wamich's data [41], can be neglected in calculating $x_{\text {Si }}$ (see Appendix).

The hyper-eutectic alloys were aged for only $128 \mathrm{~h}$ at $445 \mathrm{~K}$. It is suggested that the aluminium precipitation in these alloys has not finished. Thus the lattice parameter of the Si-rich phase at this stage can be still larger than that of pure silicon. 
TABLE V The effect on the silicon lattice parameter after completed precipitation resulting from the difference in thermal expansion between the Al-rich phase and the silicon phase (for symbols see text)

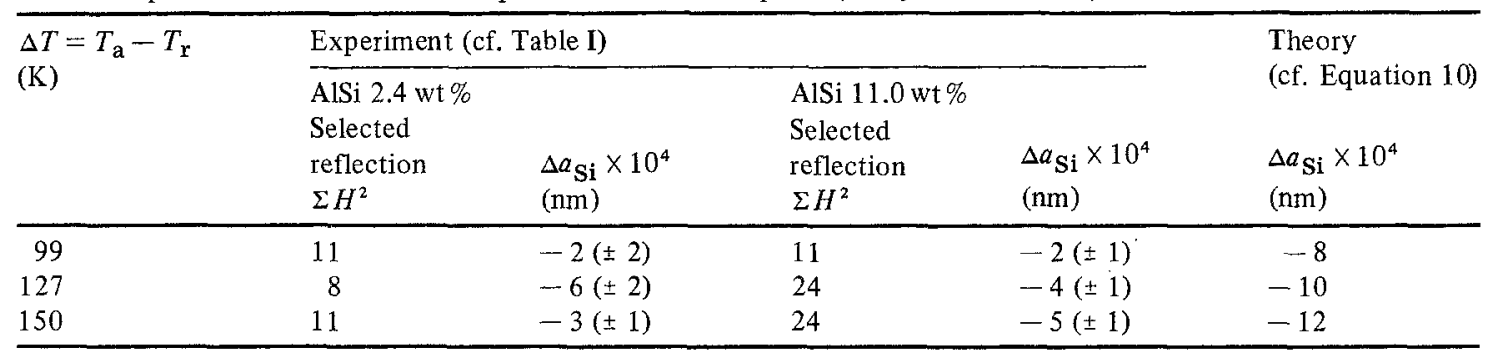

elastically isotropic material, the fractional volume change $\Delta V_{\mathrm{B}} / V_{\mathrm{B}}$ of a misfitting spherical inclusion $B$ in a finite matrix $A$ can be written as (cf. Equation 25.7 [38]):

$$
\frac{\Delta V_{\mathrm{B}}}{V_{\mathrm{B}}}=4 \pi C \epsilon \frac{\left(r_{0}^{\mathrm{A}}\right)^{3}}{V_{\mathrm{B}}}
$$

with $C=3 K_{\mathrm{B}} /\left(3 K_{\mathrm{B}}+4 \mu_{\mathrm{A}}\right)$, where $K$ and $\mu$ denote the bulk and shear modulus, respectively, and $V_{\mathrm{B}}$, the volume of the "free" undeformed inclusion $=(4 / 3) \pi\left(r_{0}^{B}\right)^{3}$.

Supposing that an individual inclusion experiences no interaction with other inclusions, then the fractional volume change is independent of the volume fraction of the inclusions present. Approximating the actual radius of the inclusion by $r_{0}^{\mathrm{B}}$ and $\Delta V_{\mathrm{B}} / V_{\mathrm{B}}$ by $3 \Delta a_{\mathrm{B}} / a_{\mathrm{B}}$ and substituting $r_{0}^{\mathrm{A}}$ by $r_{0}^{\mathrm{B}} /(1+\epsilon)(\mathrm{cf}$. Equation 8) one obtains:

$\Delta a_{\mathrm{B}}=a_{\mathrm{B}} C \epsilon /(1+\epsilon)^{3} \simeq a_{\mathrm{B}} C\left(\alpha_{\mathrm{B}}-\alpha_{\mathrm{A}}\right)\left(T_{\mathrm{a}}-T_{\mathrm{r}}\right)^{*}$

where $\alpha_{\mathrm{B}}$ and $\alpha_{\mathrm{A}}$ are the linear thermal expansion coefficients of $B$ and $A$, respectively.

In Table $\mathrm{V}$ the theoretically obtained $\Delta a_{\mathrm{Si}^{-}}$ values for the Si-rich phase (calculated using the elastic constants according to [43]) are presented, together with the experimentally obtained differences between the measured lattice parameter, $a_{\mathrm{m}}$, and the equilibrium value, $a_{\mathrm{Si}}$, for both alloys. The following can be remarked:

(i) According to Equation 10 the value of $\Delta a_{\mathrm{Si}}$ is independent of the amount of silicon present and it increases with increasing values of $\Delta T=$ $T_{\mathrm{a}}-T_{\mathrm{r}}$. This corresponds with the experimental data.

(ii) In view of the large experimental errors (silicon is the minority phase), the simplicity of the model applied and considering the question of the compatability of the elastic constants used, a quantitative agreement between experiment and theory cannot be expected. The differences between experiment and theory may be interpreted such, that in the theoretical calculations "modified" elastical constants should be used instead of literature data (see also [25]).

\subsection{Lattice microstrains and crystallite size}

\subsubsection{Lattice microstrains}

5.7.1.1. As-liquid-quenched. Quenched-in stresses, lattice defects, concentration variations and misfit between constituting phases $[2,26]$ give rise to strain broadening. Since for the Al-rich phase $(1 / E)_{100}>(1 / E)_{211}[43]$, larger strains may be expected in a [100] direction than in a [2 111$]$ direction (see Figs. 5 and 6 at $t=0$ ).

For the studied crystallographic directions of the Si-rich phase $(1 / E)$ is smallest in a [1 111$]$ direction and largest in a [311] direction [43]. Hence, the largest strain may be expected in a [3 11 ] direction and the smallest in a [1 111$]$ direction (see Fig. 7 at $t=0$ ).

5.7.1.2. During precipitation. At the start of ageing the quenched-in stresses disappear, which contributes to the decrease of the microstrain. On the other hand precipitation will introduce transformation stresses which are not readily dissipitated at an ageing temperature of $445 \mathrm{~K}$. (cf. Section 5.3.2).

The fraction of the volume affected by the transformation strains will be larger for the (minority) Si-rich phase than for the Al-rich phase. Hence, the average microstrain of the Si-rich phase will be more influenced by the transformation strains than the average microstrain of the Al-rich

${ }^{*}$ In case of the AlSi system $a_{\mathbf{B}}$ equals $a_{\mathbf{S i}}=0.54307(\mathrm{~nm})$ and $\left(\alpha_{\mathbf{B}}-\alpha_{\mathbf{A}}\right)=\left(\alpha_{\mathbf{S i}}-\alpha_{\mathrm{Al}}\right)=-20.5 \times 10^{-6} \mathrm{~K}^{-1}[29,43$, $44]$. 
phase. Accordingly, after an initial decrease of the microstrains in the $\mathrm{Si}$-rich phase these microstrains may increase again, as is observed for the [111], [110] and [311] direction (Fig. 7). The magnitude of this effect is largest in a [111] direction, which may be related to the preference of silicon particles in line their $\{111\}$ planes parallel to the interface with the Al-rich phase (cf. [4]).

After completed precipitation no effects due to transformation strains are expected. Indeed, for ageing times $>8 \frac{1}{4} \mathrm{~h}$ at $445 \mathrm{~K}$ the microstrains in the silicon phase start to decrease again.

5.7.1.3. During coarsening. After completed precipitation (time $>$ about $8 \frac{1}{4} \mathrm{~h}$ at $445 \mathrm{~K}$ ) the microstrains decrease with increasing ageing time (Figs. 5 to 7). However, a substantial microstrain remains even after $730 \mathrm{~h}$ ageing at $445 \mathrm{~K}$ (Table II). In our opinion this phenomenon is due to the difference in thermal expansion between the Al-rich phase and silicon precipitates (which effect was also responsible for the macrostrains observed in the aluminium matrix and silicon precipitates after completed precipitation (see [25] and Sections 5.1 and 5.6). Thus it may be expected that the microstrains in the Al-rich phase increase with increasing silicon content of the alloy. This corresponds with the experimental result (Table II; and compare Figs. 5 and 6 ).

As the ripening process proceeds the area of interface between the Al-rich phase and silicon particles decreases. Hence, on coarsening the fraction of the volume affected by the thermal stresses will diminish for both phases. Accordingly these microstrains should decrease with increasing coarsening time, as is observed (Figs. 5 and 6).

A quantitative prediction of $\left\langle e^{2}\right\rangle^{1 / 2}$ after $730 \mathrm{~h}$ at $445 \mathrm{~K}$ (i.e. an average value for the phase considered), is difficult to make. The microstrain due to the difference in thermal expansion will be largest near the interface of the Al-rich and Si-rich phase. An order of magnitude for this local micro. strain may be obtained by equating the tensile stress along the interface in the $\mathrm{Al}$-rich phase to the compressive stress along the interface in the $\mathrm{Si}$ rich phase [cf. 45]. Thus, the following estimates are obtained:

$$
\begin{aligned}
& e_{\mathrm{Al}}=\frac{E_{\mathrm{Si}}}{\left(E_{\mathrm{Si}}+E_{\mathrm{Al}}\right)} \epsilon=+0.9 \times 10^{-3} \\
& e_{\mathrm{Si}}=\frac{E_{\mathrm{Al}}}{\left(E_{\mathrm{Si}}+E_{\mathrm{Al}}\right)} \epsilon=-2.1 \times 10^{-3} .
\end{aligned}
$$

The value of the misfit $\epsilon$ due to the difference in thermal expansion can be obtained from Equation 10. The elastic data are taken from [43]. Indeed, (i) after $730 \mathrm{~h}$ ageing at $445 \mathrm{~K}$ the average microstrain values, $\left\langle e^{2}\right\rangle^{1 / 2}$, are in general smaller than the above estimated local strains and (ii) the $\left\langle e^{2}\right\rangle^{1 / 2}$-values observed for the Al-rich phase are smaller than for the Si-rich particles (Table II), but the averaging noted in Section 5.7.1.2 also contributes to this effect. The latter effect also suggests that the microstrain in the Al-rich phase will be larger for the AlSi $13.0 \mathrm{wt} \%$ alloy than for the AlSi $2.6 \mathrm{wt} \%$ alloy (Table II and Figs. 5 and 6) and vice versa for the Si-rich phase (Table II).

\subsubsection{Crystallite size}

On ageing the crystallite (domain) size of the silicon precipitates increases (Fig. 8). The domain sizes measured in a [1 111$]$ direction are the smallest, which may be related to the preference of silicon particles to line their $\{111\}$ planes parallel to the interface with the Al-rich phase [4].

At the start of precipitation the growth rate of the average domain size is low, as nucleation of new crystallites occurs. After nucleation the growth of the silicon particles is facilitated by the presence of remaining excess vacancies which enhance the silicon diffusion through the aluminium matrix (see Section 5.4).

According to [22] silicon precipitate needles grow along [1 110$]$ directions. This corresponds to a larger growth rate in this direction (Fig. 8).

At later, coarsening stages, less or no excess vacancies will be present. During the coarsening stage particle growth proceeds by dissolving small particles in favour of large particles (Ostwald ripening). Thus, silicon atoms contributing to particle growth have to cover larger diffusion distances in the coarsening stage as compared to the precipitation stage. The above considerations both suggest, that in the coarsening stage the growth rate of the average crystallite is smaller than during precipitation. This is supported by Fig. 8 (note logarithmic time scale).

\section{Conclusions}

1. "Free" excess vacancies, i.e. not bound to silicon, are induced by liquid quenching. At the start of ageing these "free" excess vacancies are annihilated. At relatively low ageing temperatures this gives rise to the anomalous Hump I in the 
curve of the Al-rich phase lattice parameter against ageing time.

2. The large difference between the atomic volume of silicon as dissolved in the Al-matrix and of silicon as precipitated evokes precipitation stresses. At high ageing temperatures these stresses are not readily dissipated by the accompanying recovery. This causes Hump II in the curve of the Al-rich phase lattice parameter against ageing temperature.

3. At the start of ageing quenched-in vacancies give rise to rather low values of the activation energy for precipitation. As precipitation proceeds, excess vacancies initially bound to silicon are annihilated gradually, thus enhancing the activation energy for silicon precipitation.

4. Liquid quenching of hyper-eutectic $\mathrm{AlSi}$ alloys yields a Si-rich phase, supersaturated with aluminium, as indicated by a decrease of the $\mathrm{Si}$ rich phase lattice parameter on ageing.

5. The microstrain in the Al-rich phase decreases with increasing ageing time. The influence of the precipitation stresses on the microstrain is not observed: being the majority phase, only a small volume fraction of the Al-rich phase is affected by the precipitation stresses, in contrast with the $\mathrm{Si}$ rich phase.

6. The microstrain in the Si-rich phase initially decreases on ageing, since quenched-in stresses are dissipated. Then as a result of the precipitation stresses induced, the microstrain increases, in particular in the [1 111$]$ direction. During coarsening the microstrain decreases again. The remaining microstrain as observed at room temperature is determined by the difference in thermal expansion between the aluminium and silicon phases. During precipitation the growth of the Si-particles is largest in the [1 10$]$ direction.

\section{Acknowledgements}

We are grateful to Professor B. M. Korevaar for stimulating discussions. X-ray facilities were provided by Ing. N. M. van der Pers. Dr R. Delhez made available to us computer programs for $\mathrm{X}$-ray diffraction line profile analysis. We are obliged to Ir. A. Bendijk for providing the specimens.

\section{Appendix}

Consider 1 gram mole alloy with an overall atomic fraction $x_{0}$ of silicon. If $s$ gram mole silicon has been dissolved in the Al-rich phase then the atomic fraction, $x_{\mathrm{Si}}$, dissolved is given by:

$$
\begin{aligned}
x_{\mathrm{Si}} & =s /\left(1-x_{0}+s\right) \quad \text { and thus } \\
s & =x_{\mathrm{Si}}\left(1-x_{0}\right) /\left(1-x_{\mathrm{Si}}\right) .
\end{aligned}
$$

Assuming that at the ageing temperatures applied a negligible amount of aluminium will be dissolved in the silicon phase ([37]; Section 5.5) the amount of Al-rich phase reads: $\left(1-x_{0}+s\right)=$ $\left(1-x_{0}\right) /\left(1-x_{\mathrm{Si}}\right)$.

Accordingly, the quantity of silicon not dissolved in the Al-rich phase equals: $\left(x_{0}-s\right)=$ $\left(x_{0}-x_{\mathrm{Si}}\right) /\left(1-x_{\mathrm{Si}}\right)$.

The volumes of the Al-rich phase and the silicon phase are given by $\left(1-x_{0}\right)(N / 4) a_{\mathrm{m}}^{3} /\left(1-x_{\mathrm{Si}}\right)$ and $\left(x_{0}-x_{\mathrm{Si}}\right)(N / 8) a_{\mathrm{Si}}^{3} /\left(1-x_{\mathrm{Si}}\right)$, respectively, where $N$ is Avogadro's number, $a_{\mathrm{Si}}$ is the lattice parameter of the silicon phase and $a_{\mathrm{m}}$ is the lattice parameter of the Al-rich phase.

The volume fraction of the silicon can now be written as:

$$
y_{\mathrm{Si}}=\frac{a_{\mathrm{Si}}^{3}}{2 a_{\mathrm{m}}^{3}\left(1-x_{0}\right) /\left(x_{0}-x_{\mathrm{Si}}\right)+a_{\mathrm{Si}}^{3}} .
$$

\section{References}

1. M. ITAGAKI, B. C. GIESSEN and N. J. GRANT, Trans. ASM 61 (1968) 330.

2. A. BENDIJK, R. DELHEZ, L. KATGERMAN, Th. H. de KEIJSER, E. J. MITTEMEIJER and N. M. VAN DER PERS, J. Mater. Sci. 15 (1980) 2803.

3. H. S. ROSENBAUM and D. TURNBULL, Acto Metall. 6 (1958) 653.

4. Idem, ibid. 7 (1959) 664.

5. A. SAULNiER, Mem. Sci. Rev. Métall. LVIII (1961) 615.

6. E. OZAWA and H. KIMURA, Acta Metall. 18 (1970) 995.

7. Idem, Mater. Sci. Eng. 8 (1971) 327.

8. W. KOSTER and W. KNORR, Z. Metallkd. 45 (1954) 616.

9. H. MATYJA, K. C. RUSSELL, B. C. GIESSEN and N. J. GRANT, Met. Trans. A 6A (1975) 6249.

10. J. A. WERT, Acta Metall. 28 (1980) 1361.

11. J. B. M. NUYTEN, Thesis, Technological University of Delft (1970).

12. R. W. BALLUFFI, K. H. LIE and D. N. SEIDMAN, in "Vacancies and Interstitials in Metals", edited by A. Seeger, D. Schumacher, W. Schilling and J. Diehl (North Holland Publishing Corp., Amsterdam, 1969) p. 125.

13. D. KUHLMANN-WILSDORF and H. G. F. WILSDORF, J. Appl. Phys. 31 (1960) 516.

14. M. KIRITANI, J, Phys. Soc. Jpn. 19 (1964) 618.

15. Idem, ibid. 20 (1965) 1854.

16. P. B. HIRSCH, J. SILCOX, R. E. SMALLMAN and K. H. WESTMACOTT, Phil. Mag. 3 (1958) 897.

17. W. DeSORBO and D. TURNBULl, Acta Metall. 7 (1959) 83.

18. Idem, Phys. Rev. 115 (1959) 560. 
19. C. PANSERI and T. FEDERIGHI, Phil. Mag. 3 (1958) 1223.

20. W. M. LOMER, in "Vacancies and Other Point Defects in Metals and Alloys", Institute of Metals, Monograph and report series, no. 23 (The Institute of Metals, London, 1958) p. 79.

21. F. W. SCHAPINK, Thesis, Technological University of Delft (1969).

22. K. H. WESTMACOTT, R. S. BARNES, D. HULL and R. E. SMALLMAN, Phil. Mag. 6 (1961) 939.

23. G. THOMAS and R. H. WILLENS, Acta Metall. 12 (1964) 191.

24. H. JONES, Proceedings of a Conference on Point Defect Behaviour and Diffusional Processes, Bristol, Septem ber 1976, edited by R. E. Smallman and J. E. Harris (The Metals Society, London, 1976) p. 175.

25. E. J. MITTEMEIJER, P. VAN MOURIK and Th. H. DE KEIJSER, Phil. Mag. A. 43 (1981) 1157.

26. R. DELHEZ, Th. H. DE KEIJSER, E. J. MITTEMEIJER, P. VAN MOURIK, N. M. VAN DER PERS, L. KATGERMAN and W. E. ZALM, J. Mater. Sci. 17 (1982) 2887.

27. Th. H. DE KEIJSER, J. I. LANGFORD, E. J. MITTEMEIJER and A. B. P. VOGELS, J. Appl. Cryst. 15 (1982) 308.

28. H. P. KLUG and L. E. ALEXANDER, "X-ray Diffraction Procedures" 2nd edn (John Wiley and Sons, New York, 1974).

29. W. B. PEARSON, "Handbook of Lattice Spacings and Structures of Metals" Vol. 2 (Pergamon Press, London, 1967).

30. R. K. NANDI and S. P. SEN GUPTA, J. Appl. Cryst. 11 (1978) 6.
31. H. J. AXON and W. HUME-ROTHERY, Proc. Roy. Soc. London 193A (1948) 1.

32. O. D. SHERBY, J. L. ROBBINS and A. GOLDBERG, J. Appl. Phys. 41 (1970) 3961.

33. R. O. SIMMONS and R. W. BALlUFFI, Phys. Rev. 117 (1960) 52.

34. A. PHILLIPS and R. M. BRICK, Trans. AJMME Inst. Met. 111 (1934) 94.

35. L. W. KEMPF, H. L. HOPKINS and E. V. IVANSO, ibid. 111 (1934) 158.

36. R. M. BRICK, A. PHILLIPS and A. J. SMITH, ibid. 117 (1935) 102.

37. L. F. MONDOLFO, "Aluminium Alloys, Structures and Properties" (Butterworths, London, 1976).

38. J. W. CHRISTIAN, "The Theory of Transformations in Metals and Alloys" 2nd edn, Part I (Pergamon Press, Oxford, 1975) pp. 542 and 201.

39. A. BEERWALD, Z. Electrochem. 45 (1939) 789.

40. J. BURKE, "The Kinetics of Phase Transformations in Metals" (Pergamon Press, Oxford, 1965) p. 80.

41. F. WAMICH, Thesis, Technological University of Aachen, Aachen (1965).

42. J. D. ESHELBY, Solid State Phys. 3 (1956) 79.

43. C. J.SMITHELLS, "Metals Reference Book" 5th edn (Butterworths, London, 1976).

44. R. B. ROBERTS, "Thermal Expansion", edited by I. D. Peggs (Plenum, New York, 1978) p. 189.

45. W. BOAS and R. W. K. HONEYCOMBE, Proc. Roy. Soc. London 186A (1946) 57.

Received 10 January

and accepted 20 January 1983 